\title{
Maternal age-specific risk of non-chromosomal anomalies
}

\author{
M Loane, ${ }^{a}$ H Dolk, ${ }^{a}$ JK Morris ${ }^{b}$, a EUROCAT Working Group ${ }^{a, *}$ \\ ${ }^{a}$ EUROCAT, University of Ulster, Jordanstown, UK ${ }^{b}$ Barts and the London School of Medicine and Dentistry, London, UK \\ Correspondence: M Loane, Room 12L09, Faculty of Life \& Health Science, University of Ulster, Jordanstown, Co Antrim, BT37 0QB, UK. \\ Emailma.loane@ulster.ac.uk
}

Accepted 7 April 2009. Published Online 29 May 2009.

Objectives To determine the excess risk of non-chromosomal congenital anomaly (NCA) among teenage mothers and older mothers.

Design and setting Population-based prevalence study using data from EUROCAT congenital anomaly registers in 23 regions of Europe in 15 countries, covering a total of 1.75 million births from 2000 to 2004 .

Participants A total of 38958 cases of NCA that were live births, fetal deaths with gestational age $\geq 20$ weeks or terminations of pregnancy following prenatal diagnosis of a congenital anomaly.

Main outcome measures Prevalence of NCA according to maternal age, and relative risk (RR) of NCA and 84 standard NCA subgroups compared with mothers aged 25-29.

Results The crude prevalence of all NCA was 26.5 per 1000 births in teenage mothers ( $<20$ years), 23.8 for mothers $20-24$ years, 22.5 for mothers $25-29$ years, 21.5 for mothers $30-34$ years, 21.4 for mothers $35-39$ years and 22.6 for mothers $40-44$ years. The RR adjusted for country for teenage mothers was 1.11 (95\% CI
1.06-1.17); 0.99 (95\% CI 0.96-1.02) for mothers 35-39; and 1.01 (95\% CI 0.95-1.07) for mothers 40-44. The pattern of maternal age-related risk varied significantly between countries: France, Ireland and Portugal had higher RR for teenage mothers, Germany and Poland had higher RR for older mothers. The maternal age-specific RR varied for different NCAs. Teenage mothers were at a significantly greater risk $(P<0.01)$ of gastroschisis, maternal infection syndromes, tricuspid atresia, anencephalus, nervous system and digestive system anomalies while older mothers were at a significantly greater risk $(P<0.01)$ of fetal alcohol syndrome, encephalocele, oesophageal atresia and thanatophoric dwarfism.

Conclusions Clinical and public health interventions are needed to reduce environmental risk factors for NCA, giving special attention to young mothers among whom some risk factors are more prevalent. Reassurance can be given to older mothers that their age in itself does not confer extra risk for NCA.

Keywords Maternal age, non-chromosomal anomalies, older mothers, prevalence, relative risk, teenage mothers.

Please cite this paper as: Loane M, Dolk H, Morris J, a EUROCAT Working Group. Maternal age-specific risk of non-chromosomal anomalies. BJOG 2009;116:1111-1119.

\section{Introduction}

It is well known that older mothers have a higher risk of chromosomal anomalies such as Down syndrome, ${ }^{1,2}$ but whether they are at excess risk of non-chromosomal congenital anomalies (NCA) is less clear. At the other end of the maternal age spectrum, teenage mothers have a low risk of chromosomal trisomy, but a higher risk of some $\mathrm{NCA}^{3}{ }^{3}$ in particular the abdominal wall defect gastroschisis. ${ }^{4-6}$ Maternal age may be an indicator of intrinsic biologic factors and previous reproductive history (including parity) or extrinsic factors, such as education, nutritional

${ }^{\star}$ Members of the EUROCAT Working Group are listed in Appendix. status or social and behavioural influences. If maternal age risks are related to extrinsic factors rather than intrinsic biological factors, they can be expected to vary both geographically and in time. Risk may be associated with current or past exposures. Cohorts of mothers may differ in risk according to the year they were born rather than their age at delivery. Advanced maternal age may also be associated with a differentially increased risk of miscarrying an affected fetus.

In the last two decades, the maternal age profile of the population has changed markedly in Europe, with average maternal age rising each year. It is important to have accurate information on maternal age-specific risks of NCA to gauge the implications of this rise in maternal 
age for public health, for clinical care needs and for providing information to women of childbearing age. Some of the older literature on maternal age risks is difficult to interpret, since it is likely that chromosomal anomalies in babies with structural malformations were underdiagnosed, thus creating artefactually increased risks for older mothers of apparently non-chromosomal anomalies. ${ }^{7}$ Many studies have been too small to consider mothers over 40 specifically, or to provide precise estimates for specific types of NCA.

The persistent high rate of teenage pregnancy in some European populations is of continuing concern, 8,9 especially its relationship with deprivation and unplanned pregnancy. ${ }^{10,11}$ This group experiences poorer pregnancy outcomes overall ${ }^{12,13}$ due both to their unfavourable environment and biologic immaturity. ${ }^{14}$ There is little information from Europe on the overall risk of NCA in teenage mothers.

EUROCAT is a network of population-based congenital anomaly registers covering nearly one-third of births in Europe, with a standardised methodology. In this paper, we analyse the EUROCAT database to determine maternal age-specific risks of NCA.

\section{Method}

The EUROCAT database consists of all cases of congenital malformations notified by regional or national registries including live born cases, cases resulting in fetal deaths from 20 weeks gestation and cases that were subsequently terminated following prenatal diagnosis of a congenital malformation. Twenty-three regional registries in 15 European countries participated in the study, all of which could provide maternal age data for both cases and population, for the period 2000-2004. Information on each of the registries and their methods of case ascertainment can be found on the EUROCAT website. ${ }^{15}$ Maternal age was defined as age at delivery of baby and was known for $97 \%$ of NCA cases. The remaining 3\% of cases with unknown maternal age were excluded.

Congenital anomaly cases are coded within the range 740-759 in ICD9 or the Q chapter in ICD10 code (International Classification of Disease). One case can have up to nine malformation or syndrome codes. The EUROCAT Data Management Program (EDMP) automatically assigns all congenital anomaly codes to one of 84 EUROCAT NCA subgroups (see 'EUROCAT Guide 1.3: Instructions for the registration and surveillance of congenital anomalies' for the list of subgroups and codes). ${ }^{16} \mathrm{~A}$ case can be counted only once in each subgroup but may be counted within more than one subgroup. All cases with a diagnosis coded within ICD9/BPA 758.00-758.99 and ICD10 Q90.0-Q99.9, excluding microdeletions and balanced translocations, are classified as chromosomal anomalies and excluded from this study. For comparative purposes only, a dataset of these chromosomal cases was extracted for the same registries and time period in order to calculate the maternal age-specific prevalence of chromosomal cases.

The number of births (live and still) by maternal age group was supplied by the participating registries, obtained from appropriate statistical agencies or hospitals within the areas. Maternal age was known for $97 \%$ of births in the study population. The remaining 3\% were assumed to follow the same maternal age distribution as those of known maternal age, within each registry and year.

\section{Statistical analysis}

Maternal age was categorised into 7 age-bands $(<20,20-24$, 25-29, 30-34, 35-39, 40-44 and 45+ years) and prevalence rates per 1000 births were calculated within each maternal age group as:

number of cases among livebirths + fetal deaths

( $\geq 20$ weeks gestation) + terminations of pregnancies

(TOPFA) following prenatal diagnosis of malformation/

total number of livebirths and stillbirths in the population

A Poisson regression model using STATA version 9.0 (StataCorp LP, College Station, TX, USA) was used to derive maternal age-specific relative risks (RR) relative to the 25- to 29-year age group baseline. This baseline group was chosen as it is in the middle of the age range (one age category removed from ages $<20$ and over 35) and is commonly used as a standard baseline in the literature. A model for all NCA first adjusting for country was fitted. Adjustment for country was designed to adjust for the possibility that countries with high proportions of mothers in any one age group also had generally high NCA prevalence, and that this would bias the RR estimates between age groups. A second model, after excluding mothers $45+$, allowed for interaction between country and maternal age using the UK as an arbitrary baseline country. We give country-specific results by multiplying the UK RR by the country-specific RR for each maternal age group. A third model for each of the 84 NCA subgroups adjusting for country was fitted, which did not allow for interactions due to the lack of statistical power. Because of the large number of subgroups and the problem of spuriously statistically significant results by multiple testing, only NCA subgroups with significantly increased risk at $P<0.01$ level are presented in the Results. Full results for all 84 subgroups are available online in the Appendix (S1). Risk estimates for the mothers $45+$ years are not shown where small numbers led to very large standard 
errors (Appendix S1). Maternal age was modelled as a categorical variable in order to investigate maternal age risk curves of any shape.

\section{Results}

\section{Maternal age population distribution}

Overall in 2000-2004, 4\% of mothers in the population were aged $<20$ years, $14 \%$ were aged $20-24$ years, $28 \%$ were aged 25-29 years, 34\% were aged 30-34 years, 17\% were aged 35-39 years, 3\% were $40-44$ years and $0.14 \%$ were aged 45 years and older. These proportions are generally consistent with the European Union maternal age distribution based on EUROSTAT figures for livebirths in the same countries and time period. ${ }^{17}$

Table 1 shows the geographical variation in the proportion of younger ( $<20$ years) and older mothers $(40+$ years) between countries, 2000-2004. The proportion of teenage mothers ranged from $<2 \%$ in France, Italy, the Netherlands, Spain and Switzerland to $9 \%$ in the UK. The proportion of mothers 35 years and over ranged from $9 \%$ in Poland to $25 \%-28 \%$ in France, Italy and Spain. The proportion of mothers 40 years and over ranged from $<2 \%$ in Belgium, Croatia, Denmark, Germany and Poland to $6 \%$ in France.

\section{Maternal age prevalence and risk}

Between 2000 and 2004, there were 38958 cases of NCA reported among 1.74 million births (including 61 cases born to mothers aged $45+$ years), giving a total prevalence

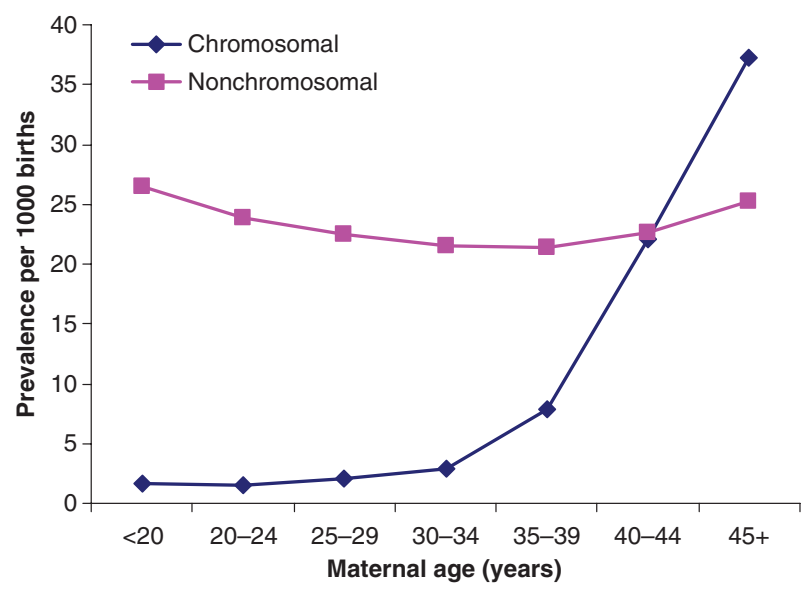

Figure 1. Prevalence of non-chromosomal anomalies and chromosomal anomalies according to maternal age, 2000-2004.

of 22.4 per 1000 births. Livebirths accounted for $88.8 \%$ of all NCA, stillbirths $1.5 \%$ and termination of pregnancy (TOPFA) $9.7 \%$ of all NCA. Mothers aged 45 years and older had the highest proportion of stillbirths (3\%) while mothers aged 35-39 and 40-44 years had the highest proportion of TOPFAs (11\% each). The crude prevalence of all NCAs according to maternal age is shown in Figure 1. Teenage mothers had the highest prevalence of all NCA (26.5 per 1000 births). Prevalence decreased as maternal age increased (23.8 per 1000 births for mothers 20-24 years, 22.5 per 1000 births for mothers 25-29 years, 21.5 for mothers 30-34 years, 21.4 for mothers

Table 1. Total births and the proportion of births according to maternal age for each country from 2000 to 2004

\begin{tabular}{|c|c|c|c|c|c|c|}
\hline & \multirow[t]{2}{*}{ Total births } & \multicolumn{5}{|c|}{ Maternal age in years $(\%)$} \\
\hline & & $<20$ & $20-34$ & $35-39$ & $40-44$ & $45+$ \\
\hline Austria & 52194 & 4 & 82 & 12 & 2 & 0.07 \\
\hline Belgium & 89189 & 2 & 85 & 11 & 2 & 0.09 \\
\hline Croatia & 27998 & 6 & 83 & 9 & 2 & 0.08 \\
\hline Denmark & 26745 & 2 & 83 & 13 & 2 & 0.05 \\
\hline France & 245903 & 1 & 74 & 20 & 5 & 0.29 \\
\hline Germany & 104574 & 7 & 81 & 10 & 2 & 0.07 \\
\hline Ireland & 164629 & 5 & 72 & 19 & 3 & 0.11 \\
\hline Italy & 276955 & 1 & 73 & 21 & 4 & 0.14 \\
\hline Malta & 19803 & 6 & 82 & 9 & 2 & 0.08 \\
\hline The Netherlands & 100552 & 1 & 79 & 17 & 2 & 0.09 \\
\hline Poland & 170725 & 6 & 85 & 7 & 2 & 0.09 \\
\hline Portugal & 56648 & 7 & 80 & 11 & 2 & 0.18 \\
\hline Spain & 179907 & 2 & 70 & 24 & 4 & 0.16 \\
\hline Switzerland & 35652 & 1 & 78 & 18 & 3 & 0.10 \\
\hline UK & 189244 & 9 & 75 & 13 & 3 & 0.12 \\
\hline Total & 1740718 & 4 & 77 & 16 & 3 & 0.14 \\
\hline
\end{tabular}


35-39 years), until a slight increase in mothers 40-44 years (22.6 per 1000 births) and a further increase in mothers $45+$ years (25.3 per 1000 births). The prevalence of all chromosomal anomalies is shown for comparison-for mothers 40-44, the risk of chromosomal and NCA are similar. Chromosomal anomalies surpass NCAs in risk for mothers 45 and over.

Table 2 shows the RR of all NCAs according to maternal age compared with mothers aged 25-29 for all countries combined and for all individual countries. The RR for teenage mothers (compared with mothers aged 25-29) of NCA, adjusted for country, was 1.11 ; 95\% CI 1.06-1.17. Mothers between 25 and 44 years had the lowest risk of NCA. Mothers $45+$ had the same RR as teenage mothers, but it was not statistically significant in this age group $(\mathrm{RR}=1.11,95 \%$ CI $0.87-1.43$, data not shown $)$.

A model including interaction between maternal age and country was found to provide a significantly better fit $(P<0.001)$. In the UK (baseline country), the risk of NCA was 1.09 in teenage mothers, 0.96 in mothers 35-39 and 1.06 in mothers 40-44 years (Table 2). Teenage mothers in France, Ireland and Portugal had a significantly greater RR of NCAs (relative to mothers aged 25-29) than teenage mothers in the UK. Mothers 35-39 years in Austria, Germany and Poland and mothers 40-44 years in Germany had significantly greater RR of NCA compared with the RR of their UK counterparts (Table 2). Mothers 35-39 and 40-44 years in France and the Netherlands had significantly lower RR of NCA compared with older mothers in UK.

Table 3 shows the specific NCAs for which teenage mothers had significantly increased risk $(P<0.01)$ compared with mothers aged 25-29. Teenage mothers were six times more likely to have a baby with gastroschisis (RR 6.32, 95\% CI 4.75-8.41) and almost five times more likely to have malformations resulting from three maternal infections [congenital rubella, congenital cytomegalovirus (CMV) and congenital toxoplasmosis] during the first trimester of pregnancy (RR 4.57, 95\% CI 2.24-9.32) compared with 25- to 29-year-old mothers. Teenage mothers had a nearly three-fold greater risk of having a baby with tricuspid atresia and stenosis $(\mathrm{RR}=2.63,95 \% \quad \mathrm{CI}$ 1.37-5.06) compared with baseline mothers. Teenage mothers were also at greater risk of having a baby with anencephalus $(\mathrm{RR}=1.74,95 \%$ CI 1.22-2.47), nervous system anomalies (RR 1.39, 95\% CI 1.20-1.61), digestive system anomalies ( $\mathrm{RR}=1.31,95 \%$ CI $1.09-1.57)$ and abdominal wall defects (RR 3.52 95\% CI 2.80-4.44).

Table 3 shows the specific NCAs for which older mothers, either 35-39 years or 40-44 years, had significantly increased risk compared with mothers aged 25-29. Older mothers were 7-12 times more likely to have babies with fetal alcohol syndrome (mothers 35-39 years: RR 7.13; 95\% CI 2.31-22.03; mothers 40-44 years: RR 11.66; 95\%
CI 2.89-47.07). Mothers 35-39 years were at greater risk of having a baby with thanatophoric dwarfism (RR 2.59; 95\% CI 1.32-5.08), but no increased risk was found in mothers 40-44 years compared with baseline mothers. An increased risk of encephalocele was found in babies born to mothers over 40 (RR 2.36; 95\% CI 1.25-4.48), but not in mothers 35-39 years, compared with baseline mothers. A similar age-specific RR was found in the offspring of mothers over 40 for oesophageal atresia (RR 2.10; 95\% CI 1.32-3.35), but not in mothers 35-39 compared with the baseline.

A 'U-shaped' distribution curve with younger and older mothers showing significantly increased risk was reported for respiratory anomalies $(P<0.001)$ (Appendix S1). Teenage mothers had a $50 \%$ increased risk of having babies with respiratory anomalies while mothers over 40 years had a $43 \%$ increased risk compared with 25- to 29-year-old mothers (Appendix S1).

The Appendix lists the RR for all NCA subgroups according to maternal age compared with women aged 25-29, together with the statistical significance of any maternal age effect. As a large numbers of comparisons are being made there will be spurious statistically significant results and therefore care must be taken in interpreting individual statistically significant results.

\section{Discussion}

Overall in Europe, we find that teenage mothers are at higher risk of NCA, but older mothers 35-44 years are not. However, the maternal age pattern of risk differs between countries, suggesting that it is not biological age that is associated with risk of NCA, but reproductive (including parity and use of Assisted Reproductive Technology), social, ethnic, exposure or lifestyle factors that have a different relationship with maternal age in different European countries. We should therefore expect apparently conflicting results between published studies of different populations, as has indeed been found in the past. This finding is in contrast to the older maternal age-related risks for chromosomal anomalies such as Down's syndrome, which are the same across different countries, indicative of intrinsic biological risk factors. ${ }^{18,19}$

The sharp increase in average maternal age has led to public health concerns over worsening pregnancy outcomes. ${ }^{20}$ Our results show that older maternal age is a negligible risk factor for NCAs, especially when compared to chromosomal anomalies. Since the rise in maternal age in Europe is especially associated with women of higher social status, it may have resulted in decreasing NCA risks in this age group compared to past decades. ${ }^{21}$ Nevertheless, in some countries, particularly Germany and Poland, older maternal age seems to be a more important risk factor. 


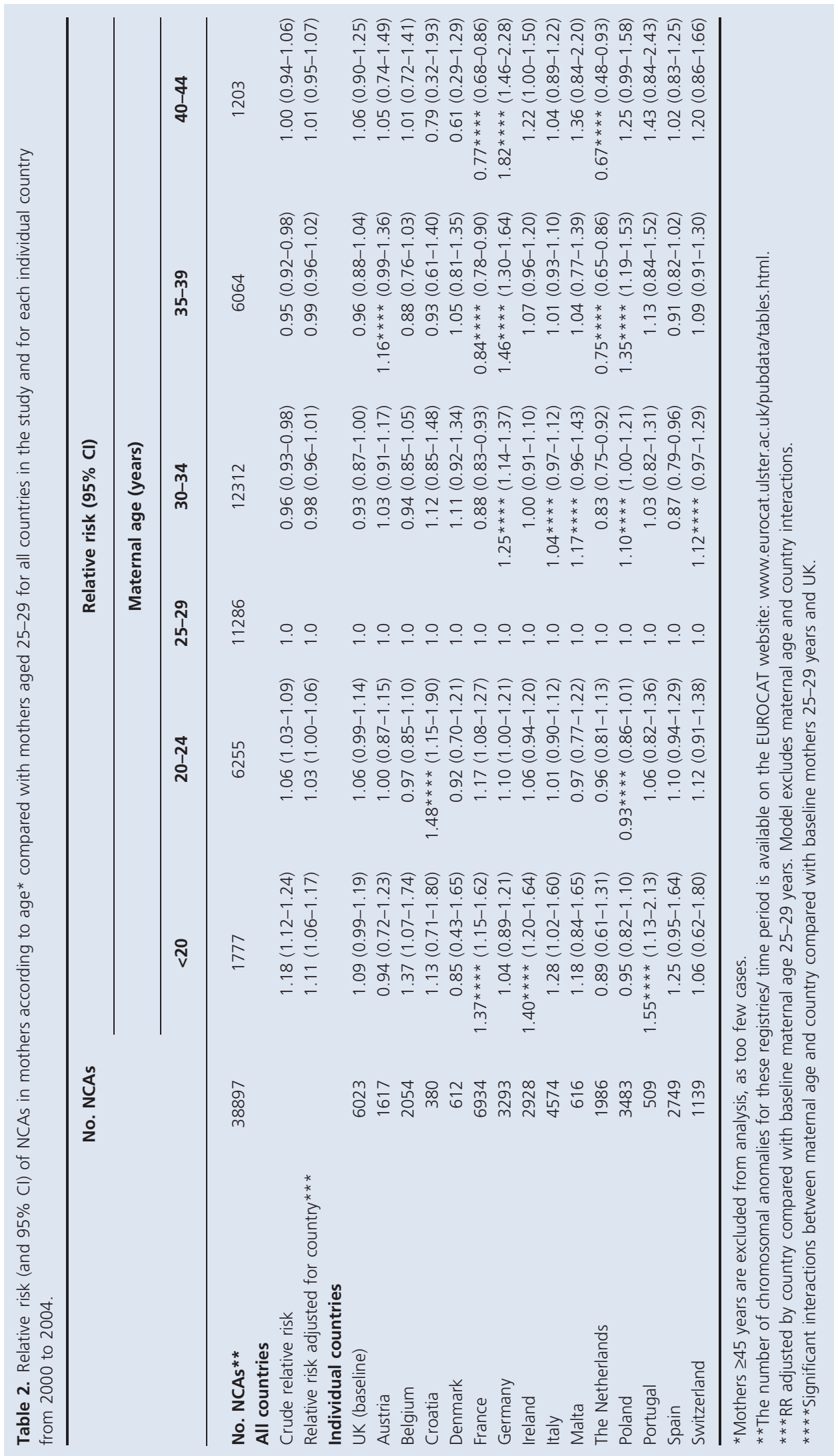


Table 3. Adjusted relative risk* for congenital anomalies with significantly greater risk in mothers $<20$ years, and in mothers $35-39$ years or 40-44 years compared with mothers aged 25-29, EUROCAT registries from 15 countries combined, 2000-2004

\begin{tabular}{|c|c|c|c|}
\hline NCA & $n$ & $\mathbf{R R}$ & $95 \% \mathrm{Cl}$ \\
\hline & \multicolumn{3}{|c|}{ Mothers $<20$ years } \\
\hline Nervous system & 215 & 1.39 & $(1.20-1.61)$ \\
\hline Anencephalus and similar & 40 & 1.74 & $(1.22-2.47)$ \\
\hline Tricuspid atresia and stenosis & 12 & 2.63 & $(1.37-5.06)$ \\
\hline Digestive system & 136 & 1.31 & $(1.09-1.57)$ \\
\hline Abdominal wall defects & 113 & 3.52 & $(2.80-4.44)$ \\
\hline Gastroschisis & 98 & 6.32 & $(4.75-8.41)$ \\
\hline \multirow[t]{2}{*}{ Maternal infection syndromes** } & 13 & 4.57 & $(2.24-9.32)$ \\
\hline & \multicolumn{3}{|c|}{ Mothers $35-39,40-44$ years } \\
\hline Encephalocele 35-39 & 35 & 1.39 & $(0.89-2.17)$ \\
\hline Encephalocele 40-44 & 12 & 2.36 & $(1.25-4.48)$ \\
\hline Oesophageal atresia 35-39 & 69 & 1.28 & $(0.93-1.75)$ \\
\hline Oesophageal atresia 40-44 & 22 & 2.10 & $(1.32-3.35)$ \\
\hline Thanatophoric dwarfism 35-39 & 21 & 2.59 & $(1.32-5.08)$ \\
\hline Thanatophoric dwarfism 40-44 & 1 & 0.62 & $(0.08-4.75)$ \\
\hline Fetal alcohol syndrome 35-39 & 13 & 7.13 & $(2.31-22.03)$ \\
\hline Fetal alcohol syndrome $40-44$ & 4 & 11.66 & $(2.89-47.07)$ \\
\hline
\end{tabular}

This may be associated with risk factors more prevalent among these mothers either during the years of the study (2000-2004) or in their earlier lives.

Compared with the middle of the age range (25-29 years), teenage mothers had an $11 \%$ excess risk (95\% CI 6-17\%). This finding is consistent with findings from North America, ${ }^{3,22,23}$ but some countries (particularly France, Ireland and Portugal) had higher risks than others. Teenage mothers had a five times increased risk (and mothers 20-24 years had double the risk) of maternal infection syndromes compared with mothers aged 25-29 years. Congenital CMV infection accounted for all but two of the 13 maternal infection cases in teenage mothers in our study. Maternal age $<25$ years and recent onset of sexual activity are known risk factors for $\mathrm{CMV}^{24}$ In addition, hydrocephaly, microcephaly and gastroschisis have been associated with maternal infections, ${ }^{25,26}$ and it is possible that higher risks for these malformations among teenage mothers are mediated in part by undiagnosed infection.

The high risk of the abdominal wall defect gastroschisis in young mothers is well known. ${ }^{4-6}$ Although social deprivation, substance abuse, smoking and low body mass index have been indicated by aetiologic studies as risk factors for gastroschisis, a complete explanation of the young maternal age risk has not been found. It may be that these mothers are in addition more biologically vulnerable to these risk factors. Vascular disruption has been proposed as a pathogenic mechanism underlying the risk of certain types of NCA, including gastroschisis, in young mothers, ${ }^{27-29}$ but not all anomalies that have been associated with vascular disruption showed higher risks in teenage mothers in this study.

The high risk of anencephalus, in teenage mothers has previously been reported ${ }^{3}$ and may relate to lower folic acid status because of poorer nutrition or lower periconceptional folic acid supplementation rates associated with unplanned pregnancies and lower socioeconomic status. ${ }^{30}$ However, the lack of risk in teenage mothers for spina bifida suggests other factors are also important.

Mothers who survived congenital heart defects as infants are now giving birth (although some high risk mothers are advised not to get pregnant), and may be at greater risk of having children with the same or different anomalies. ${ }^{31,32}$ In this regard, the surveillance of prevalence of babies with congenital heart disease among younger mothers is of interest. The finding regarding risks of tricuspid atresia among teenage mothers needs confirmation in further studies, as the risk estimate is based on a small number of cases, but is unlikely to be explained by such a survival effect.

Despite the lack of overall increased risk in older mothers, there were some specific congenital anomaly subgroups which did show a significantly increased risk worthy of comment. Our finding that fetal alcohol syndrome is strongly associated with older maternal age needs further follow up. Fetal alcohol syndrome is underascertained by 
most congenital anomaly registers as it is often diagnosed after the first year of life and usually does not involve major structural malformations. Our finding, although based on small numbers, could indicate that older mothers are more vulnerable to alcohol effects with respect to malformation risk, or that they are more frequently heavy alcohol consumers periconceptionally, or that their chronic consumption results in different risks from teenage binge drinking, or that they are more likely to be known to clinicians as heavy alcohol consumers.

Thanatophoric dwarfism is associated with new mutations known to be related to older paternal age. ${ }^{33}$ It is therefore not surprising that we find an effect of older maternal age (35-39 years). There was little statistical power to investigate the over 40-year age group.

Our finding of an increased risk for oesophageal atresia (with or without fistula) among older mothers is consistent with the findings of a Swedish case-control study 1982$2004,{ }^{34}$ but is contrary to an earlier European study which found an increased risk for younger mothers $<20$ years in $1980-88 .^{35}$ This could be indicative of a cohort effect as the older mothers in this study and the younger mothers in the earlier European study were born in the 1960s. The increased risk of encephalocele among older mothers seems also to be counter to previous findings. ${ }^{3,36}$ It must be borne in mind, that inconsistent findings in the literature may be due to chance differences as a result of multiple testing in this and other studies.

The strengths of this study are the large size of the study population combined with high case ascertainment, standardised methodology and specific diagnostic information. However, even in such a large study, there is not sufficient statistical power to examine whether maternal age-specific RR for specific congenital anomaly subgroups vary between countries because of their individual rarity. We would have liked to analyse information in the database on parity-among NCA cases, $80 \%$ of teenage mothers were primiparous compared with $55 \%$ of mothers $20-24,46 \%$ of mothers $25-29,34 \%$ of mothers $30-34$, $23 \%$ of mothers $35-39$ and $18 \%$ of mothers $40+$ years. However, there is no comparable population information on parity for most of the populations included. This highlights the importance of developing general perinatal information for Europe. ${ }^{37}$

A number of artefacts can lead to small apparent agerelated risk increases. Mismatches between numerator and denominator can bias estimates of risk. For example, we did not correct TOPFA for age at expected delivery, which means that mothers aged 19 that had a TOPFA, may well have been in the 20-24 age group if they had gone to term. This would lead to there being slightly more cases of congenital anomaly in mothers $<20$ years compared with the corresponding birth population. However, since only $7 \%$ of teenage mothers had terminations of pregnancy, and of those $61 \%$ were under 19 years, this would not explain excess risk in this age group. For mothers 40-44, lack of age correction of terminations would have underestimated the age-related risk slightly.

Since we only include spontaneous fetal deaths from 20 weeks gestation, it is of course possible that different maternal age effects would be found if all incident cases during pregnancy could be considered, because of differential in utero survival effects. Older mothers have an increased risk of stillbirth and early miscarriage ${ }^{38,39}$ and it is possible that this applies particularly to more vulnerable malformed fetuses. The increased risk of multiple births to mothers 35-39 years and the increased risk of congenital anomalies among multiple births (5\% of our NCA cases were multiple births) also need further investigation in relation to older maternal age risks.

Clinical and public health interventions are needed to reduce environmental risk factors for NCA, giving special attention to young mothers among whom some risk factors are more prevalent. Reassurance can be given to older mothers that their age in itself does not confer extra risk for NCA.

\section{Disclosure of interests}

None.

\section{Contribution to authorship}

ML and HD defined the research question, designed the study, interpreted the analysis and co-wrote the paper. ML also prepared and analysed the data. JM provided statistical analysis expertise, interpreted the data and commented on drafts of the paper. The EUROCAT Working Group provided the data and commented and approved the final version of the paper.

\section{Details of ethics approval}

This paper was conducted as part of the European Surveillance of Congenital Anomalies study (Approved 23rd August 2006; Ref no: REC/06/72). In addition, all registries have ethical approval appropriate to their national and local ethics guidelines.

\section{Funding}

EUROCAT is supported by the EU Commission Public Health Directorate Public Health Programme. The funders had no involvement in the study design, analysis of data, write-up of the report or decision to submit for publication.

\section{Acknowledgements}

We thank the EUROCAT registry leaders for providing data. 


\section{Supporting information}

The following supplementary materials are available for this article:

Appendix S1. Maternal age relative risk adjusted for country compared with baseline maternal age 25-29 years.

Additional Supporting Information may be found in the online version of this article.

Please note: Wiley-Blackwell are not responsible for the content or functionality of any supporting information supplied by the authors. Any queries (other than missing material) should be directed to the corresponding author.

\section{References}

1 Sherman SL, Allen EG, Bean LH, Freeman SB. Epidemiology of Down syndrome. Ment Retard Dev Disabil Res Rev 2007;13:221-7.

2 Hollier LM, Leveno KJ, Kelly MA, McIntire DD, Cunningham FG. Maternal age and malformations in singleton births. Obstet Gynecol 2000;96:701-6.

3 Reefhuis R, Honein MA. Maternal age and non-chromosomal birth defects, Atlanta - 1968-2000: teenager or thirty-something, who is at risk? Birth Defects Res (Part A) 2004;70:572-9.

4 Loane M, Dolk H, Bradbury I, a EUROCAT Working Group. Increasing prevalence of gastroschisis in Europe 1980-2002: a phenomenon restricted to younger mothers? Paediatr Perinat Epidemiol 2007;21:363-9.

5 Kazaura R, Lie T, Irgens LM, Didriksen A, Kapstad M, Egenaes J, et al. Increasing risk of gastroschisis in Norway: an age-period-cohort analysis. Am J Epidemiol 2004;159:358-63.

6 Calzolari E, Bianchi F, Dolk H, Milan M. Omphalocele and gastroschisis in Europe: a survey of 3 million births 1980-1990. EUROCAT Working Group. Am J Med Genet 1995;58:187-94.

7 Hay S, Barbano $\mathrm{H}$. Independent effects of maternal age and birth order on the incidence of selected congenital malformations. Teratology 1972;6:271-80.

8 Tripp J, Viner R. Sexual health, contraception and teenage pregnancy. BMJ 2007;330:590-3.

9 Lawlor DA, Shaw M. Teenage pregnancy rates: high compared with where and when? J R Soc Med 2004;97:121-3.

10 Olausson PO, Haglund B, Weitoft G, Cnattingius S. Teenage childbearing and long-term socioeconomic consequences: a case study in Sweden. Fam Plann Perspect 2001;33:70-4.

11 Koniak-Griffin D, Turner-Pluta C. Health risks and psychosocial outcomes of early childbearing: a review of the literature. J Perinat Neonatal Nurs 2001;15:1-17.

12 Miller B, Brent C, Benson B, Galbraith KA. Family relationships and adolescent pregnancy risk: a research synthesis. Dev Rev 2001;21: $1-38$

13 Botting M, Rosato M, Woods R. Teenage mothers and the health of their children. Popul Trends 1998;93 (Autumn):19-28.

14 Bateman BT, Simpson LL. Higher rate of stillbirth at the extremes of reproductive age: a large nationwide sample of deliveries in the United States. Am J Obstet Gynecol 2006;194:840-5.

15 EUROCAT member registries [www.eurocat.ulster.ac.uk/memberreg/ memberreg.html]. Accessed 29 September 2008.

16 EUROCAT Guide 1.3 Instructions for the registration and surveillance of congenital anomalies [www.eurocat.ulster.ac.uk/pdf/ EUROCAT-Guide-1.3.pdf]. Accessed 29 September 2008.
17 EC maternal age distribution. EUROSTAT [http://epp.eurostat.ec. europa.eu/portal/page/portal/population/data/database]. Accessed 5 May 2009.

18 Morris JK, Wald NJ, Mutton DE, Alberman E. Comparison of models of maternal age-specific risk for Down syndrome live births. Prenat Diagn 2003;23:252-8.

19 Dolk H, Loane M, Garne E, De Walle H, Queisser Luft A, de Vigan $C$, et al. Trends and geographic inequalities in the livebirth prevalence of Down syndrome in Europe, 1980-1999. Revue Epidemiol Sante Publique 2005;53:2587-95.

20 Nabukera S, Wingate MS, Alexanderr GR, Salihu HM. First-time births among women 30 years and older in the United States: patterns and risk of adverse outcomes. J Reprod Med 2006;51: 676-82.

21 Yang J, Carmichael SL, Canfield M, Song J, Shaw GM. National Birth Defects Prevention Study. Socioeconomic status in relation to selected birth defects in a large multicentered US case-control study. Am J Epidemiol 2008;167:145-54.

22 Baird PA, Sadovnick AD, Yee IML. Maternal age and birth defects: a population study. Lancet 1991;337:527-30.

23 Croen LA, Shaw GM. Young maternal age and congenital malformations: a population-based study. Am J Public Health 1995;85:710-3.

24 Fowler KB, Pass RF. Risk factors for congenital cytomegalovirus infection in the offspring of young women: exposure to young children and recent onset of sexual activity. Pediatrics 2006;118: e286-92.

25 Munro SC, Trincado D, Hall B, Rawlinson WD. Symptomatic infant characteristics of congenital cytomegalovirus disease in Australia. J Paediatr Child Health 2005;41:449-52.

26 Feldkamp ML, Reefhuis J, Kucik J, Krikov S, Wilson A, Moore CA, et al. Case-control study of self reported genitourinary infections and risk of gastroschisis: findings from the national birth defects prevention study, 1997-2003. BMJ 2008;336:1420-3.

27 Curry CJ, Lammer EJ, Nelson V, Shaw GM. Schizencephaly: heterogeneous etiologies in a population of 4 million California births. Am J Med Genet 2005;137A:181-9.

28 Lubinsky MS. Association of prenatal vascular disruptions with decreased maternal age. Am J Med Genet 1997;69:237-9.

29 Holmes LB. Teratogen-induced limb defects. Am J Med Genet 2002;112:297-303.

30 de Walle HEK, de Jong-van den Berg LTW. Ten years after the Dutch public health campaign on folic acid: the continuing challenge. Eur J Clin Pharmacol 2008;64:539-43.

31 Thilen U, Olsson SB. Pregnancy and heart disease: a review. Eur J Obstet Gynecol 1997;75:43-50.

32 Gill HK, Splitt M, Sharland GK, Simpson JM. Patterns of recurrence of congenital heart disease. J Am Coll Cardiol 2003;42:923-9.

33 Waller DK, Correa A, Vo TM, Wang Y, Hobbs C, Langlois PH, et al. The population-based prevalence of achondroplasia and thanatophoric dysplasia in selected regions of the US. Am J Med Genet Part A 2008;146A:2385-9.

34 Oddsberg J, Jia C, Nilsson E, Ye W, Lapergren J. Influence of maternal parity, age, and ethnicity on risk of esophageal atresia in the infant in a population-based study. J Pediatr Surg 2008;43:1660-5.

35 Depaepe A, Dolk H, Lechat MF. The epidemiology of tracheooesophageal fistula and oesophageal atresia in Europe. Arch Dis Child 1993;68:743-8.

36 Wen S, Ethen M, Langlois PH, Mitchell LE. Prevalence of Encephalocele in Texas, 1999-2002. Am J Med Genet 2007;A 15:143A:2150-5.

37 Zeitlin J, Wildman K, Bréart G, Alexander S, Barros H, Blondel B, Buitendijk S, Gissler M, Macfarlane A and The PERISTAT Scientific 
Advisory Committee. Indicators for monitoring and evaluating perinatal health in Europe. Eur J Public Health 2003;13(Suppl 1):29-37.

38 Huang L, Sauve R, Birkett N, Fergusson D, van Walraven C. Maternal age and risk of stillbirth: a systematic review. CMAJ 2008;178:165-72.

39 Maconochie N, Doyle P, Prior S, Simmons R. Risk factors for first trimester miscarriage - results from a UK-population-based casecontrol study. BJOG 2007;114:170-86.

\section{Appendix}

\section{EUROCAT Working Group}

Martin Haeusler, Styria, Austria; Vera Nelen, Antwerp, Belgium; Ingeborg Barisic, Zagreb, Croatia; Ester Garne, Odense, Denmark; Catherine de Vigan, Paris, France;
Berenice Doray, Strasbourg, France; Annette Queisser-Luft, Mainz, Germany; Simone Poetzsch, Saxony-Anhalt, Germany; Mary O’Mahony, Cork \& Kerry, Ireland; Bob Mc Donnell, Dublin, Ireland; Beth-Ann Roche, South East Ireland, Ireland; Elisa Calzolari, Emilia Romagna, Italy; Anna Pierini, Tuscany, Italy; Miriam Gatt, Malta; Hermien de Walle, the Netherlands; Anna Latos-Bielenska, Wielkopolska, Poland; Carlos Dias, Portugal; Carmen Mosquera-Tenreiro, Asturias, Spain; Joaquin Salvador, Barcelona, Spain; Isabel Portillo, Basque Country, Spain; Marie-Claude Addor, Vaud, Switzerland; Patricia Boyd, Oxford, UK; David Tucker, Wales, UK. 